\title{
AVALIAÇÃO DA INFLUÊNCIA DAS TRINCAS NO ÍNDICE DE PERMEABILIDADE MAGNÉTICA DAS PELOTAS PARA DEFINIÇÃO DE NOVO MÉTODO DE MEDIÇÃO DO FEO*
}

\author{
Heidy de Oliveira Simões ${ }^{1}$ \\ Ana Maria Guilherme Bailon ${ }^{1}$ \\ Raquel Ramos Almeida da Silva² \\ Anderson Pedruzzi ${ }^{3}$ \\ Francisco Passos Pellegrinit \\ Vinícius Perin Passigatti ${ }^{5}$ \\ Thiago Marchezi Doellinger ${ }^{6}$ \\ Maurício Cota Fonseca ${ }^{7}$
}

\section{Resumo}

O objetivo deste trabalho foi estudar as correlações entre o IPM (Índice de Permeabilidade Magnética) das pelotas queimadas, as trincas formadas durante o processamento das pelotas no pelotamento/endurecimento e o $\mathrm{FeO}$ de cada amostra. As análises evidenciaram que o tipo de trinca presente na pelota impacta no IPM fazendo diminuir a correlação entre IPM e FeO. O entendimento do fenômeno possibilitou desenvolver uma metodologia para determinação de um parâmetro que pudesse ser correlacionado ao $\mathrm{FeO}$ das pelotas de minério de ferro, estendendo sua aplicação ao pellet feed, baseado nas propriedades magnéticas do material. O método consiste em medir a variação da indutância de um solenoide, provocada pela introdução do material que se deseja determinar o parâmetro no núcleo de uma bobina, determinando-se relativamente a permeabilidade magnética das pelotas e pellet feed. Para tal, foi definida uma metodologia nas quais alterações devidas à variação da densidade da amostra, causadas principalmente devido a trincas nas pelotas, sejam mitigadas, garantindo a repetibilidade dos resultados. Assim, foi possível a determinação do $\mathrm{FeO}$ das amostras através da medição deste novo parâmetro, de forma mais rápida, fácil e com um custo consideravelmente menor que na química analítica clássica.

Palavras-chave: Pelota; Trincas; Pellet feed; Magnetismo.

\section{EVALUATION OF THE CONTENTS OF CRACKS IN MAGNETIC PERMEABILITY OF PELLETS FOR SETTING NEW METHOD OF MEASURING THE FEO}

\begin{abstract}
The work aimed at studying the correlations between the IPM (magnetic permeability index) of fired pellets, the cracks formed during the processing of agglomeration/induration and $\mathrm{FeO}$ level of each sample. The analyses showed that the kind of crack on the pellet impact on the IPM, decreasing the correlation between IPM and $\mathrm{FeO}$. The understanding of this phenomenon led to develop a methodology to determine a parameter which could be correlated with the level of FeO of the iron ore pellets, extending its application to the pellet feed (based on the magnetic properties of this material). The method consists of measuring the change in the solenoid inductance, as a consequence of the material introduction (which is desired to determine this parameter) in the core of the inductor. So, a methodology was set in which fluctuations from sample density changes (resulting mainly from the presence of cracks in the pellets) were mitigated, ensuring repeatability of the outcome. Thus, it was possible to quantify the FeO level of the samples by measuring this new parameter, which is faster, easier and with a cost considerably lower in comparison with the classical analytical methodology.

Keywords: Pellet; Cracks; Pellet Feed; Magnetism.

1 Técnico em Metalurgia e Materiais, Técnico de Processos, Eng. de Processos, Samarco Mineração, Anchieta, ES, Brasil.

2 Técnico em Mineração, Laboratorista, Eng. de Processos, Samarco Mineração, Anchieta, ES, Brasil.

3 Técnico em Metalurgia, Técnico Especialista de Processo, Samarco Mineração, Anchieta, ES, Brasil.

4 Licenciatura em Física, Analista de Desenvolvimento Tecnológico, Gerencia Geral de Tecnologia e Ecoeficiência, Samarco Mineração, Anchieta, ES, Brasil.

5 Eng. Metalúrgico, Chefe de Equipe, Engenharia de Processos, Samarco Mineração, Anchieta, ES, Brasil.

6 Eng. Metalúrgico, Chefe de Departamento, Eng. de Processos, Samarco Mineração, Anchieta, ES, Brasil.

7 Msc Metalurgia e Metalurgia e Materiais, Engenheiro Especialista, Gerencia Geral de Tecnologia e Ecoeficiência, Samarco Mineração, Anchieta, ES, Brasil.
\end{abstract}

\footnotetext{
* Contribuição técnica ao 44 Seminário de Redução de Minério de Ferro e Matérias-primas, 15은 Simpósio Brasileiro de Minério de Ferro e $2^{\circ}$ Simpósio Brasileiro de Aglomeração de Minério de Ferro, 15 a 18 de setembro de 2014, Belo Horizonte, MG, Brasil.
} 


\section{INTRODUÇÃO}

O processo metalúrgico de fabricação das pelotas tem início na obtenção da principal matéria-prima: o minério de ferro. Feitosa et al. [1] concluíram que as principais constituintes mineralógicas no minério de Alegria, usado na Samarco Mineração, são: hematita porosa (hematita martítica); especularita (hematita especular); goethita; magnetitas residuais e quartzo. O pellet feed é transformado em pelotas cruas que, para resistir às operações de manuseio e transporte até o cliente e às transformações em ferro, torna-se necessário submetê-las a um tratamento térmico cuidadoso e bem balanceado, proporcionando às mesmas a resistência física e mecânica apropriada.

\subsection{Principais Constituintes Mineralógicos}

A hematita, fórmula química $\left(\alpha-\mathrm{Fe}_{2} \mathrm{O}_{3}\right)$, caracterizada como sendo antiferromagnética, possui o maior grau possível de oxidação do ferro, com estrutura romboédrica (Figura 1a) constituída por hexágonos sobrepostos onde os íons de $\mathrm{Fe}^{3+}$ situam-se nos vértices dos hexágonos. É frequentemente muito pura e seu possível conteúdo de $\mathrm{FeO}$, sem exceção, parece ser devido a magnetita misturada, Rocha, [2]. Hematita é também o estágio final de oxidação das pelotas endurecidas.

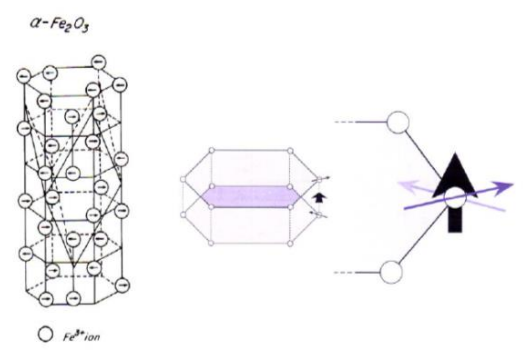

Figura 1. (a) A estrutura magnética da hematita ( $\alpha \mathrm{Fe} 2 \mathrm{O} 3$ ) [3]; (b)

Acoplamento dos íons de $\mathrm{Fe} 3+$ na hematita, situados em planos basais vizinhos. $\mathrm{O}$ acoplamento origina uma magnetização espontânea ao longo do eixo c [4].

A magnetita, fórmula química $\left(\mathrm{Fe}_{2}+\mathrm{Fe}_{2}{ }^{3+} \mathrm{O}_{4}\right.$ ou $\left.\mathrm{Fe}_{3} \mathrm{O}_{4}\right)$, onde os íons $\mathrm{Fe}^{2+}$ (ferrosos) e os íons $\mathrm{Fe}^{3+}$ (férricos) ocupam sítios bem determinados entre os íons $\mathrm{O}_{2}{ }^{-}$. É o mineral ferrimagnético mais importante da natureza e está presente em rochas ígneas, sedimentares e metamórficas. É o óxido de ferro mais antigo presente nos minérios de Alegria e ocorre formando agregados com outros minerais de ferro.

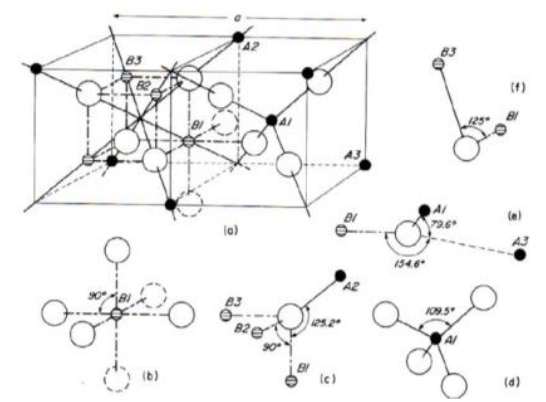

Figura 2. (a) Esquema de 1/4 da unidade da cela da magnetita [3]

Goethita, fórmula geral $\alpha-\mathrm{FeOOH}$, juntamente com a hematita, é um dos minerais predominantes na jazida de Alegria. É o óxido de ferro hidratado mais importante, capaz de preservar magnetização. Ela apresenta estrutura ortorrômbica e é

* Contribuição técnica ao 44ํㅗㄴ Seminário de Redução de Minério de Ferro e Matérias-primas, 15은 Simpósio Brasileiro de Minério de Ferro e $2^{\circ}$ Simpósio Brasileiro de Aglomeração de Minério de Ferro, 15 a 18 de setembro de 2014, Belo Horizonte, MG, Brasil. 
antiferromagnética. Durante o processo de queima da pelota, goethita é convertida em hematita por um processo endotérmico e, portanto, que aumenta o consumo de calor. Depois da secagem e preaquecimento, a limonita deixa uma estrutura porosa, o que exige maiores tempos e temperaturas para o endurecimento Meyer [5].

\subsection{Pelotas Queimadas}

As propriedades das pelotas de minério de ferro são influenciadas pela tipologia e natureza do minério ou concentrado, pelos aditivos utilizados e pelo subsequente tratamento térmico para produção das pelotas queimadas [6].

\subsubsection{Formação de Magnetita nas Pelotas Queimadas}

Simões et al [7] identificou que um dos principais fatores influenciadores da morfologia final da pelota queimada e, consequentemente, sua qualidade física, é a redução de hematita em magnetita e reoxidação de magnetita, formando hematita secundária. As pelotas com menor resistência física e possuidoras de magnetita apresentam comportamento diferente das pelotas sem magnetita e, consequentemente, com resistência mais alta. É possível que tais reações estejam tendo preferência sobre a sinterização, desta forma, a sinterização torna-se mais efetiva após a reoxidação da magnetita.

$\mathrm{O}$ indicativo da presença de magnetita $\left(\mathrm{Fe}_{3} \mathrm{O}_{4}\right)$ nas pelotas queimadas é a elevação no seu teor de $\mathrm{FeO}$, estando diretamente relacionados a uma baixa oxidação/reoxidação durante o tratamento térmico no forno de pelotização.

Fonseca et al [8] estudando a influência da dosagem de carvão na qualidade das pelotas queimadas mostrou que as análises químicas realizadas para os dois tipos de pelotas produzidas com diferentes dosagens de carvão (e, consequentemente diferentes teores de carbono na mistura) apresentaram tendência do aumento do teor de $\mathrm{FeO}$ com o aumento da dosagem de carvão. O aumento do teor de FeO com a elevação da dosagem de carvão foi observado até uma dosagem $22,5 \%$ acima do padrão. O efeito deletério de altas dosagens de carvão sobre a resistência à compressão a frio de pelotas hematíticas foi confirmado por Lu [9] e Srinivas [10] conforme mostrado na Figura 3. Este resultado pode ser interpretado devido à redução parcial da hematita para magnetita e a subsequente reoxidação incompleta da magnetita para hematita.

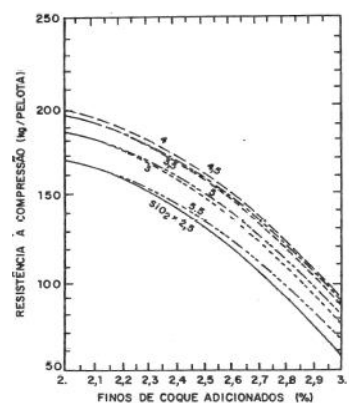

Figura 3. Efeito da adição de finos de coque sobre a resistência à compressão de pelotas de alta basicidade [9].

Durante a transformação de fase ocorrem fissuras intragranulares nos grãos de hematita original em decorrência da mudança da estrutura cristalina de $\mathrm{HC}$ (Hexagonal Compacta) para CFC (Cúbica de Face Centrada). A redução da hematita para magnetita é normalmente acompanhada de aumento de volume (Figura 4) enquanto a reoxidação da magnetita acarreta redução de volume 
(contração). Tais transformações envolvem mudança na estrutura cristalina, ocorrendo geração de tensões que conduzem ao enfraquecimento da pelota.

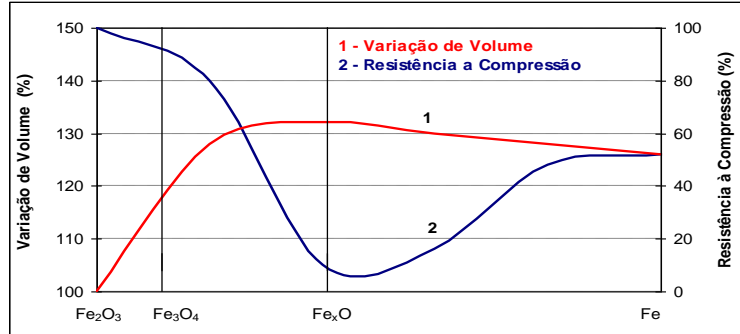

Figura 4. Relação entre mudança de volume e resistência à compressão durante a remoção do oxigênio [5].

O efeito da temperatura máxima de queima pode ser visto na Figura 5. Existe uma temperatura de queima que maximiza a resistência à compressão das pelotas. Isto pode ser entendido considerando que em temperaturas mais baixas não há formação de uma quantidade de liquido suficiente para dar resistência às pelotas, sendo que em temperaturas muito elevadas a redução de hematita a magnetita é favorecida, e, como já foi visto esta transformação enfraquece a pelota.

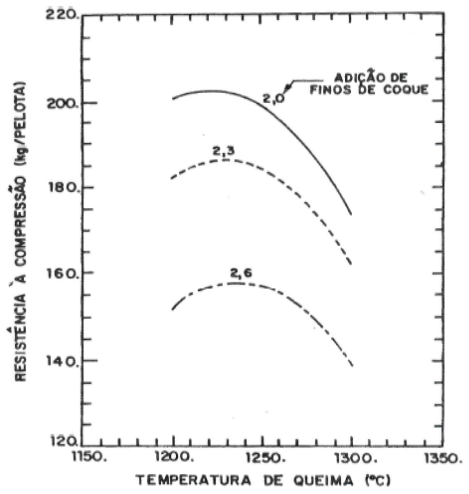

Figura 5. - Efeito da temperatura máxima de queima sobre a resistencia à compressão de pelotas de alta basicidade com diferentes adiçõoes de finos de coque [9].

\subsubsection{Formação de trincas nas pelotas queimadas}

Fonseca [11] estudando a origem de formação das trincas em pelotas queimadas identificou dois diferentes tipos de trincas, as trincas de resiliência e as trincas térmicas.

As trincas de resiliência são resultantes de esforços de compressão das pelotas nas etapas de secagem. As trincas térmicas são resultantes do choque térmico nas pelotas na transição da etapa de secagem descendente para a etapa de pré-queima, A Figura 6 mostra os dois tipos de trincas.

Trincas Térmicas

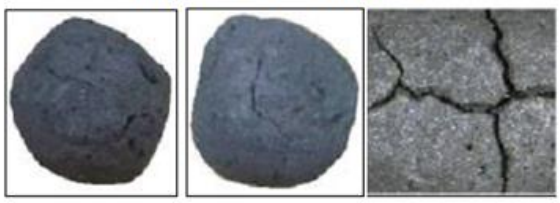

Trincas de Resiliência
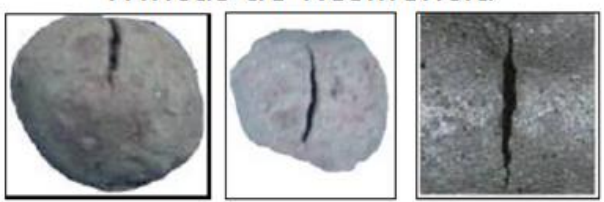

Figura 6. - Tipos de trincas presentes nas pelotas queimadas. Fonte: Fonseca [11]

\section{3 - Propriedade Magnéticas dos Materiais}

Quando um campo magnético externamente aplicado $(\mathrm{H})$, intercepta um material, a força do próprio campo exerce um torque que tende a orientar os dipolos magnéticos

* Contribuição técnica ao 44 Seminário de Redução de Minério de Ferro e Matérias-primas, 15은 Simpósio Brasileiro de Minério de Ferro e $2^{\circ}$ Simpósio Brasileiro de Aglomeração de Minério de Ferro, 15 a 18 de setembro de 2014, Belo Horizonter MG, Brasil. 
com o campo (como a agulha de uma bússola está orientada pelo campo magnético da Terra). A magnitude deste campo de força no interior do material é chamada de densidade de fluxo magnético (ou indução magnética), designado por " $B$ ".

Tanto $\mathrm{H}$ quanto $\mathrm{B}$, são vetores de campo e, portanto, são caracterizados não só pela magnitude, como também pela sua direção no espaço. A relação entre $\mathrm{B}$ e $\mathrm{H}$ é:

$$
\mathrm{B}=\mu \mathrm{H}
$$

Onde $\mu$ é chamado de permeabilidade e é dependente do meio por onde está passando o campo $\mathrm{H}$ e no qual é medido o campo B. Se o meio for o vácuo, $\mu=\mu 0$ (permeabilidade no vácuo). Dentre os parâmetros usados para descrever as propriedades magnéticas dos sólidos, está a permeabilidade relativa ( $\mu$ r) que é a razão:

$$
\mu r=\mu / \mu O
$$

A permeabilidade relativa e a permeabilidade propriamente dita de um material medem o grau no qual um material pode ser magnetizado ou a facilidade com a qual um campo $\mathrm{B}$ pode ser induzido na presença de um campo externo $\mathrm{H}$.

\section{MATERIAIS E MÉTODOS}

Foram analisadas, inicialmente, pelotas queimadas separadas segundo o tipo de trinca, provenientes de duas queimas em Pot Grate com perfis de queima diferentes e, após definição do novo método de quantificação do $\mathrm{FeO}$, foram analisadas amostras das 4 usinas da Samarco.

O IPM (Índice de Permeabilidade Magnética) das pelotas foi medido segundo método criado na Samarco, que utiliza uma ponte RLC e um solenóide com núcleo de ar. O IMP é calculado utilizando parâmetros físicos das pelotas, correlacionados à variação da indutância do solenóide, provocada pela introdução das pelotas no núcleo deste. A figura 7 mostra a ponte RCL utilizada.

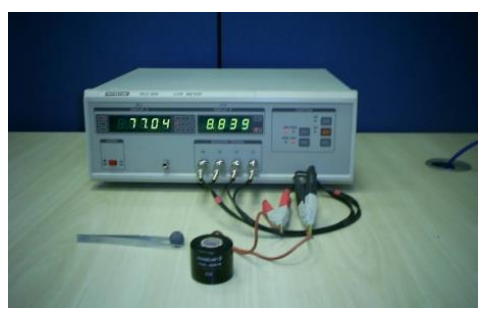

Figura 7. Ponte RLC

A quantificação das trincas foi realizada através da observação da superfície das pelotas, baseada no método descrito por Fonseca [11]. Neste trabalho as trincas foram subdivididas segundo sua resistência à compressão, desta forma: Térmica Fina, Térmica Grande; Térmica Ramificada; Resiliência Fina/Média e Resiliência Grande, conforme figura 8.
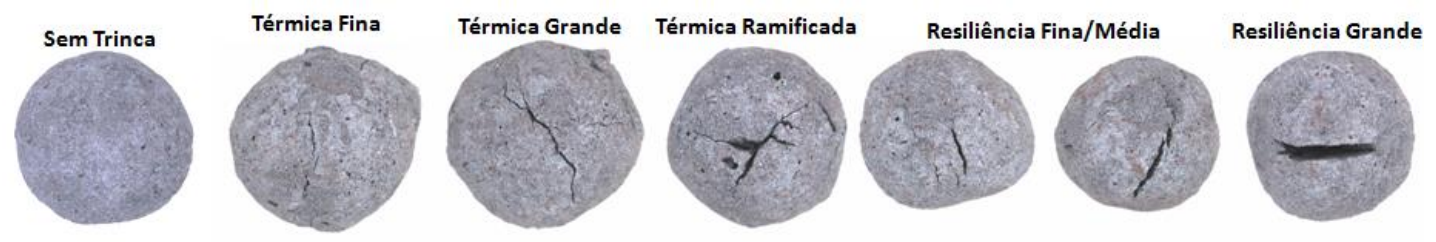

Figura 8. Tipos de trincas analisadas

* Contribuição técnica ao 44ํㅗㄴ Seminário de Redução de Minério de Ferro e Matérias-primas, 15은 Simpósio Brasileiro de Minério de Ferro e $2^{\circ}$ Simpósio Brasileiro de Aglomeração de Minério de Ferro, 15 a 18 de setembro de 2014, Belo Horizonte, MG, Brasil. 
A quantificação das fases mineralógicas foi realizada através de análise automática de imagens, analisador Axio Vision - Zeiss acoplado a microscópio óptico de luz refletida Zeiss, modelo Imager M.2m (com platina motorizada e dotado de câmera).

A quantificação do $\mathrm{FeO}$ das pelotas foi realizada através de química analítica clássica, em método baseado na norma ISO 9035 [12].

Para a determinação da resistência à compressão a frio das pelotas, utilizou-se o padrão ISO 4700 [13].

\section{RESULTADOS E DISCUSSÃO}

O IPM é utilizado na Samarco e correlaciona-se principalmente com a resistência física das pelotas, contudo, sua correlação com o $\mathrm{FeO}$ é baixa, conforme figura 9 .

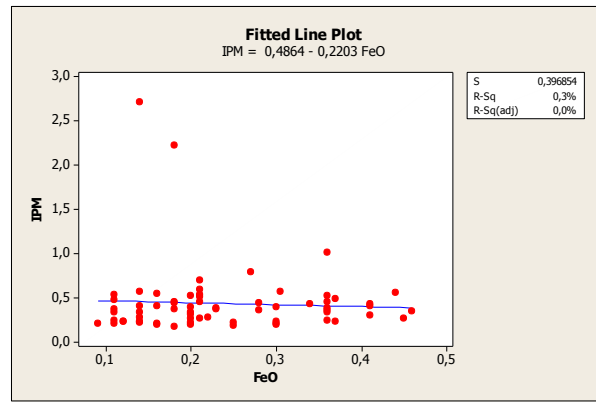

Figura 9. Correlação IPM x FeO

Buscando-se entender a não correlação dos dados, foram analisados lotes de pelotas produzidas em Pot Grate com perfis de queima diferentes, denominados Usina $\mathrm{A}$ e Usina $\mathrm{B}$, onde, além dos resultados de resistência à compressão (CCS), FeO e IPM, foram analisadas as trincas das pelotas, conforme tabela 1.

Tabela 1. Avaliação das pelotas queimadas com determinação dos tipos de trincas

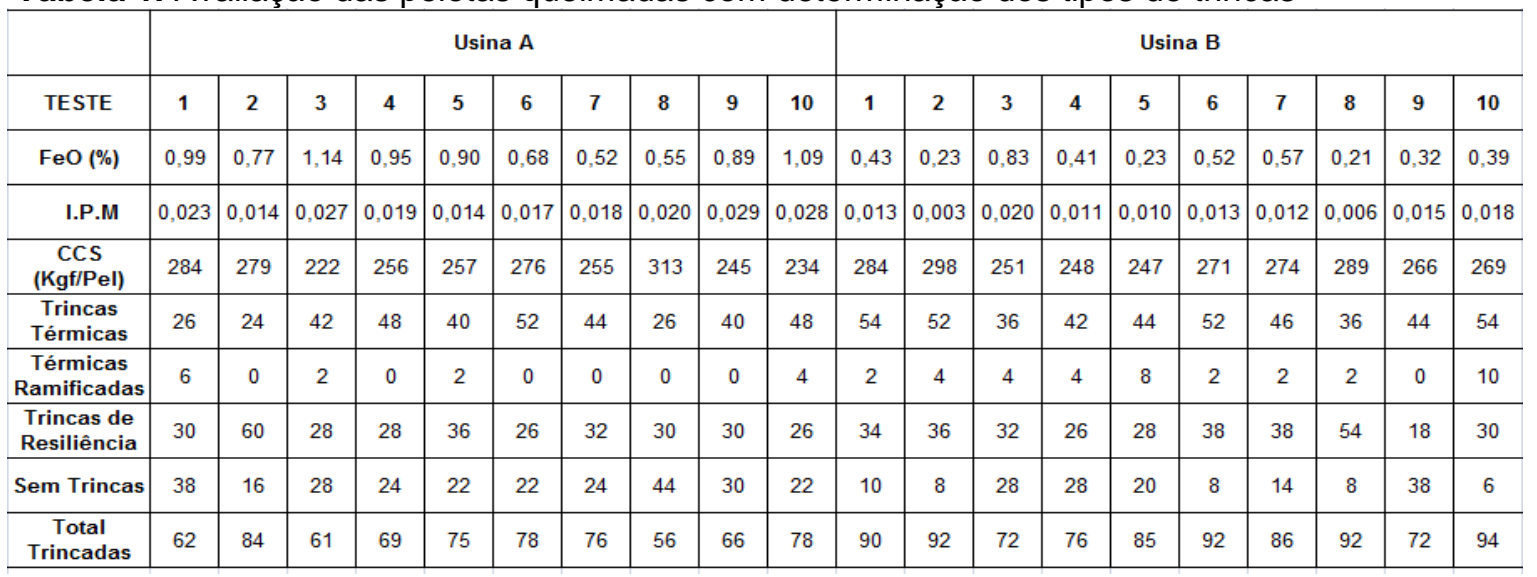

A baixa correlação entre o IPM das amostras e o FeO medido na análise química foi confirmada, conforme figura 10(a), que mostra a baixa correlação para os doi perfis de queima. Outra observação foi quanto à geração de trincas, notou-se que as pelotas do perfil com correlação entre IPM e FeO ligeiramente menor apresentou menor geração de trincas. 
IPM x FeO

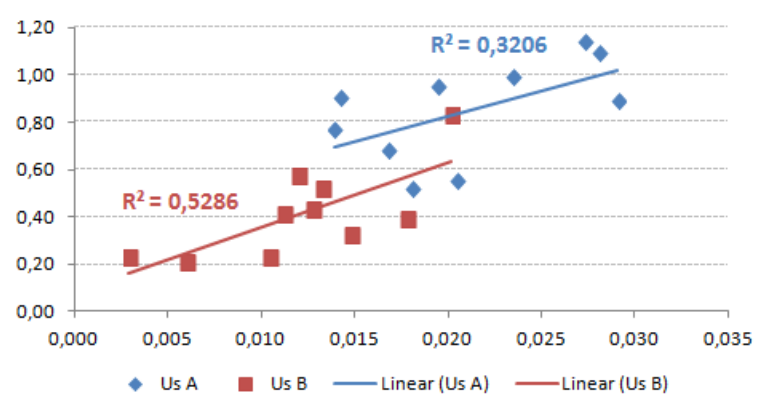

Total de Pelotas Trincadas

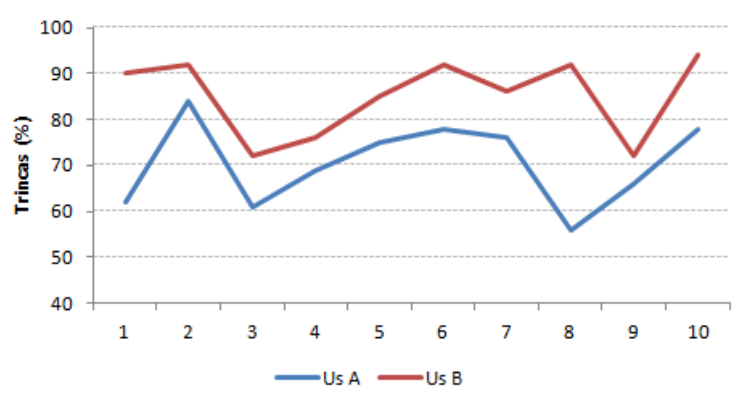

Figura 10. (a) Correlação IPM x FeO segundo a usina; (b) percentual de trincas nas pelotas segundo a usina.

Baseado nos resultados anteriores, foi calculada a média de IPM para cada tipo de trinca identificado e, como mostrado na figura 11 , notou-se que à medida que o tamanho da trinca se eleva o IPM diminui.

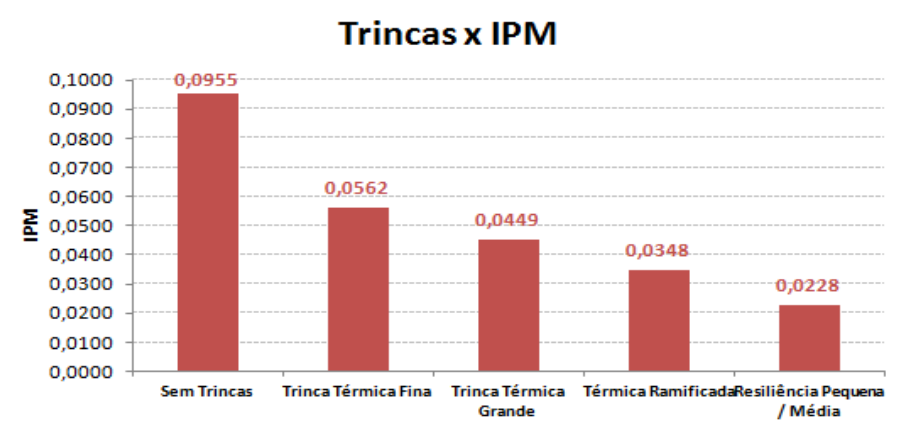

Figura 11. (a) Comportamento do IPM de acordo com o tipo de trinca

Para verificar se essa diminuição do IPM estava de fato ligada à maior reoxidação da pelota (devido a um maior contato entre a atmosfera oxidante do forno e a área superficial da pelota, com consequente diminuição do $\mathrm{FeO}$ ), ou se a sua menor densidade, foi realizada uma análise microestrutural das pelotas com os principais tipos de trincas. Neste caso, buscou-se quantificar a magnetita, conforme mostra a tabela 2.

Tabela 2. Análise Microestrutural dos tipos de trincas

\begin{tabular}{c|c|c|c|c|c}
\hline Tipo de Trinca & Poros & Hematita & Magnetita & Silicatos & Ferritos \\
\hline Trinca Térmica Fina & 41,2 & 33,3 & 19,7 & 5,3 & 0,4 \\
\hline Térmica Ramificada & 43,4 & 36,3 & 14,8 & 5,1 & 0,3 \\
\hline Resiliência Pequena / Média & 43,1 & 37,3 & 15,1 & 4,2 & 0,2 \\
\hline Resiliência Grande & 35,6 & 56,8 & 1,9 & 5,5 & 0,2 \\
\hline
\end{tabular}

As principais diferenças foram encontradas na pelota com trinca de resiliência grande, onde a presença de magnetita foi muito pequena, bem como a porosidade da amostra, evidenciando que este tipo de trinca impacta efetivamente nas reações de queima da pelota.

Quando são correlacionados os percentuais de magnetita com o IPM dos tipos de trinca, conclui-se que há grande quantidade de magnetita, contudo, o IPM diminui consideravelmente. Assim, é possível afirmar que as trincas presentes alteram a densidade da pelota e sua indutância, fazendo com que seu IPM seja menor. A figura 12 mostra a formação de magnetita $x$ o IPM das pelotas. 
Após concluir que as trincas impactavam no IPM e, consequentemente, diminuíam a correlação IPM x Magnetismo, foi desenvolvido um método para mitigar este problema.

As amostras foram pulverizadas e inseridas em um compartimento para posterior inserção na bobina para medição da diferença na indutância. O compartimento possui volume de $1 \mathrm{~cm}^{3}$, onde é colocada a massa referente ao peso específico previamente determinado. Foram realizados testes com e sem compressão do material no tubo. A figura 15 mostra o compartimento utilizado e exemplifica o teste sem compressão e com compressão.
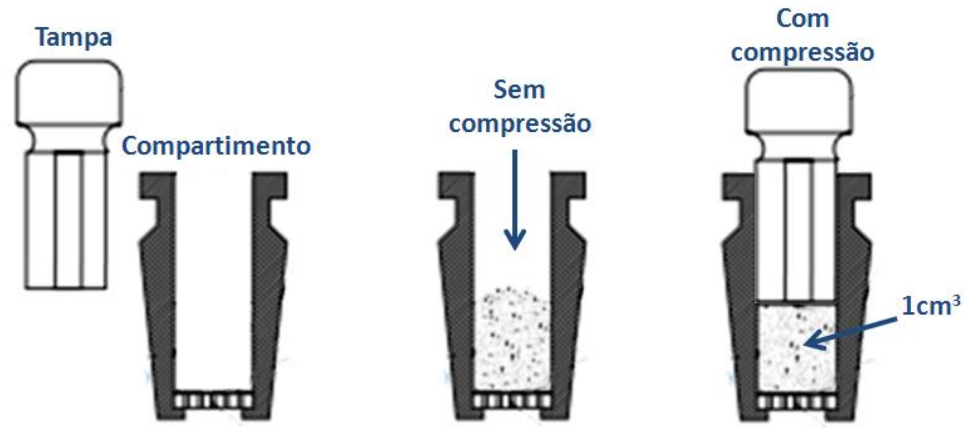

Figura 15. Compartimento utilizado (esquerda); Teste sem compressão (centro); Teste com compressão (direita)

O gráfico na figura 16(a) mostra a correlação obtida entre o método desenvolvido comprimindo o material, isto é, alocando-o efetivamente em $1 \mathrm{~cm}^{3}$, (b) sem comprimir o material e, por fim, correlacionando ambas com a análise química clássica. Notase que a compressão do material acarreta em maior correlação com o FeO
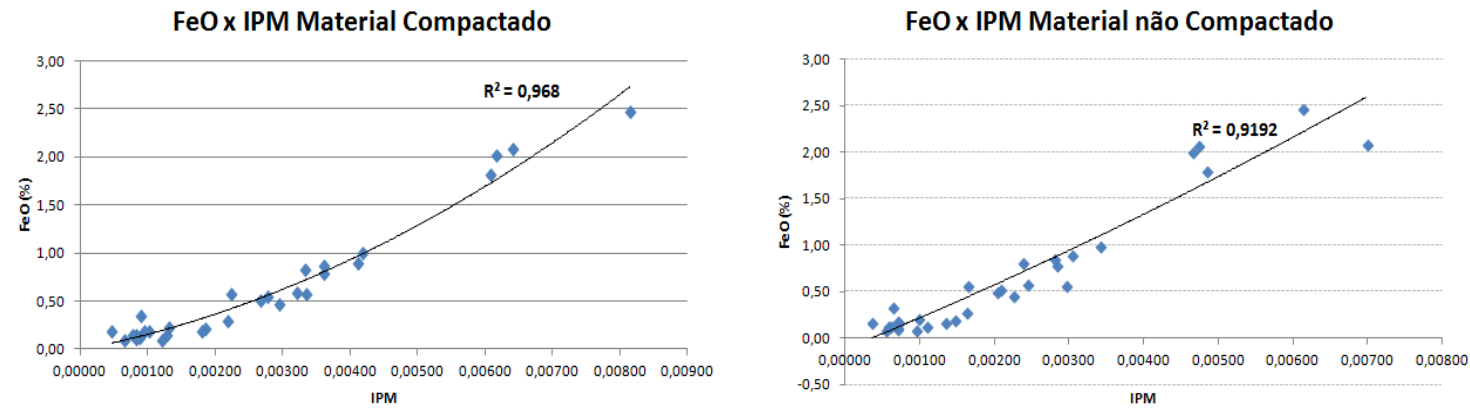

Figura 16. Correlação entre o IPM do novo método compactado (a) e sem compactar (b)

A alta correlação entre o IPM obtido com compressão no novo método e o FeO da análise química clássica permitiu a definição de uma equação através da qual podese obter o FeO diretamente através do IPM. A figura 17 mostra a correlação do FeO obtido na análise química clássica e pelo método desenvolvido.

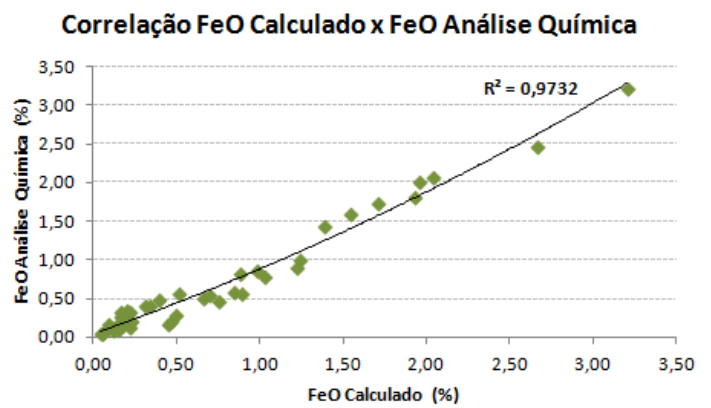

Figura 17. Correlação entre o IPM do novo método compactado (a) e sem compactar (b).

* Contribuição técnica ao 44 Seminário de Redução de Minério de Ferro e Matérias-primas, 15은 Simpósio Brasileiro de Minério de Ferro e $2^{\circ}$ Simpósio Brasileiro de Aglomeração de Minério de Ferro, 15 a 18 de setembro de 2014, Belo Horizonteo MG, Brasil. 
Este novo método de medição do FeO é rápido e eficiente. Pode ser utilizado no controle de processo, para indicar, por exemplo, se a dosagem de carvão está adequada ao processo, não gerando elevadas quantidades de magnetita e, consequentemente, acarretando em diminuição da qualidade física da pelota.

\section{CONCLUSÃO}

O IPM medido diretamente na pelota queimada possui baixa corelação com o FeO da amostra;

Amostra de pelotas com menor quantidade de trincas tendem a possuir maior correlação do seu FeO e o IPM. Quanto maiores as trincas, menor a correlação com o FeO. Trincas maiores tendem a acarretar em menor formação de magnetita no interior da pelota, o que pode ser explicado pela maior área de contato da estrutura com os gases oxidantes do forno de pelotização.

As análises microestruturais mostraram que o percentual de magnetita nas pelotas tende a diminuir com a elevação do tamanho das trincas, contudo, em proporção bem menor que a queda do IPM. A quantidade de magnetita presente nas pelotas não se reflete completamente no IPM. Tal fato foi relacionado à diferença de densidade das pelotas devido à suas trincas, que alteram a variação da indutância.

O novo método de medição do IPM, através da inserção da amostra pulverizada em compartimento desenvolvido, mostrou-se eficiente para efetivamente medir a permeabilidade magnética das amostras. A alta correlação entre o $\mathrm{FeO}$ medido na análise química clássica e o IPM no novo método possibilitou indicar o $\mathrm{FeO}$ da pelota diretamente no teste de IPM.

A medição do FeO através do novo método de quantificação do IPM mostrou-se adequado para o controle de produção, indicando, por exemplo, se a quantidade de carvão adicionada ao processo está adequada, isto é, não gerando magnetita em demasia.

\section{Agradecimentos}

Os autores agradecem a Samarco Mineração pelo suporte e incentivo e à todos que contribuíram para este trabalho, em especial a equipe do Laboratório de Desenvolvimento de Processos da Samarco.

\section{REFERÊNCIAS}

1 Feitosa VMN, Silva JP, Rabelo PJB, Coelho LH. Estudos de caracterização mineralógica e suas implicações no processo na mina de Alegria. Simpósio de Geologia de Minas Gerais, 7ํㅗ 1993 , Belo Horizonte. Anais do workshop geologia estrutural dos minérios de ferro. Belo Horizonte: FAPEMIG, 1993. p. 369-373.

2 Rocha JMP. Definição da tipologia e caracterização mineralógica e microestrutural dos itabiritos anfibolíticos das Minas de Alegria da Samarco Mineração S.A. - Minas Gerais Volume 1. Tese de Doutorado. Belo Horizonte: Universidade Federal de Minas Gerais; 2008.

3 Dunlop DJ, Özdemir Ö. 1997. Rock Magnetism. Fundamentals and Frontiers. Cambridge Studies in Magnetism Series. xxi + 573 pp. Cambridge, New York: Cambridge University Press.

4 Butler B. Paleomagnetism: Magnetic Domains to Geologic Terranes., 1992.

5 Meyer, Kurt - Pelletizing of Iron Ores. Germany: Springer - Verlag Berlin Heidelberg New York, $1980-302$ p.

6 Rigaud M, et al. - Characterization of fluxed pellets produced from low silica specular hematite - CIM Bulletin, 1992; 85(964): 102 
7 Simões $\mathrm{HO}$, et al. Desenvolvimento de uma metodologia para determinação do grau de sinterização dos grãos em pelotas de minério de ferro através de análise automática de images. 6th International Congress on the Science and Technology of Ironmaking -

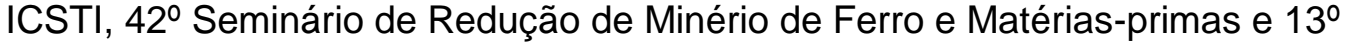
Seminário Brasileiro de Minério de Ferro, 14 a 18 de outubro de 2012, Rio de Janeiro, RJ, Brasil.

8 Fonseca MC, et al. Influência da dosagem de carvão na qualidade das pelotas queimadas. 39 Seminário de Redução de Minério de Ferro e Matérias-primas e 10ำ Seminário Brasileiro de Minério de Ferro, 22 a 26 de novembro de 2009, Ouro Preto, MG.

9 Lu WK, et al. Fluxed pellets with high coke breeze additions. In: 1990 - Ironmaking Conference Proceedings, p. 3-11

10 Srinivas, D., Gupta, P. K. and Raos, S. M. - Prediction of Iron Ore Pellet Strength Using Artificial Neural Network Model - ISIJ Interanational, Vol. 47 (2007) No. 1, p. 67-72.

11 Fonseca MC. Influência da distribuição granulométrica do pellet feed no processo de aglomeração e na qualidade da pelota de minério de ferro para redução direta - 142 páginas. Dissertação de Mestrado, REDEMAT - Ouro Preto, 2004.

12 International Organization for Standardization, BS ISO 9035:2007: Iron ores Determination of acid-soluble iron (II) content - Tritimetric method. Primeira edição, 1989.

13 International Organization for Standardization, BS ISO 4700:2007: Iron ores Determination of tumble strength, Third edition, London, November 1995.

* Contribuição técnica ao 44 Seminário de Redução de Minério de Ferro e Matérias-primas, 15은 Simpósio Brasileiro de Minério de Ferro e $2^{\circ}$ Simpósio Brasileiro de Aglomeração de Minério de Ferro, 15 a 18 de setembro de 2014, Belo Horizonte, MG, Brasil. 